
Horticultura Brasileira 24: 283-288.

\title{
Caracterização e avaliação agronômica de híbridos e linhagens de milho doce (sul)
}

\author{
Luiz Fernando G Oliveira Jr ${ }^{1}$; Messias G Pereira ${ }^{2}$; Ricardo Bressan-Smith ${ }^{2}$
}

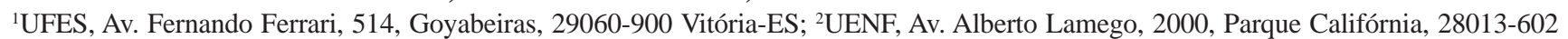
Campos dos Goytacazes-RJ; E-mail: lfg@cchn.ufes.br

\section{RESUMO}

Na safra de 2003-2004 foram avaliados em Itaocara e Campos dos Goytacazes (RJ), dois híbridos de milho-doce portadores do gene sul e um híbrido de milho-comum, juntamente com seus parentais e doadores, totalizando onze materiais. Os híbridos de milho-doce foram obtidos de cruzamentos simples e, seus parentais, a partir de retrocruzamentos. O híbrido comum foi obtido do cruzamento simples e seus parentais a partir de seleção recorrente recíproca. $\mathrm{O}$ delineamento utilizado foi blocos ao acaso com duas repetições e parcelas compostas de quatro fileiras de cinco metros cada, em dois locais. Estudou-se o comportamento dos híbridos em relação à heterose, coeficiente de determinação genotípica e caracteres morfoagronômicos. Os dois híbridos de milho-doce avaliados sobressaíram-se em relação aos seus parentais e doadores, mas não em relação ao híbrido de milho-comum. Foi detectada heterose em várias características, tais como produtividade de espigas sem palha, porcentagem de espigas atacadas por pragas, e uma forte influência genotípica, como indicado pelo coeficiente de determinação genotípica.

Palavras-chave: Zea mays L., melhoramento, caracteres morfoagronômicos, híbridos, retrocruzamento.

\begin{abstract}
Characterization and evaluation of elite sweet-corn (su1) hybrids and lines

Two sweet-corn (su-1 mutant and common-corn) hybrids, as well as the respective parentals and donators, summing up 11 genetic materials, were evaluated in two environments, in Itaocara and Campos dos Goytacazes, Rio de Janeiro State, Brazil. The sweetcorn hybrids were obtained by simple crosses between sweet-corn parentals carrying the gene $s u-1$, transferred by backcross. Heterosis, the genotypic determination coefficient and morphoagronomic traits were evaluated. The experimental design consisted of randomized blocks, with two replications in each environment. Four-row plots, 5-m long, were used. The two sweet-corn hybrids overcame their parentals and donators. Comparison between sweet- and commoncorn hybrids showed no significant differences. Heterosis was detected in almost all traits, as for example, yield of ears without straw and percent of ears damaged by pests, as well as significant genotypic influence, revealed by the genotypic determination coefficient.
\end{abstract}

Keywords: Zea mays L., breeding, morphoagronomic traits, hybrid, backcross.

(Recebido para publicação em 14 de fevereiro de 2005; aceito em 29 de agosto de 2006)

$\mathrm{O}$ milho-doce, considerado como olerícola, é um tipo especial de milho, de alto valor nutricional. Possui genes que limitam a biossíntese de amido, o que causa acúmulo de polissacarídeos solúveis de caráter adocicado no endosperma e, devido a esse baixo teor de amido, não é indicado para elaboração de pratos como pamonha e curau (Valentini et al., 2002). Pode ser utilizado em conserva (enlatado), congelado na forma de espigas ou grãos, desidratado ou consumido in natura, colhido antes da polinização e usado como "Baby Corn" ou minimilho. Após a colheita, a palhada pode ser utilizada para silagem (Souza et al., 1990; Teixeira et al., 2001).

O milho-doce é caracterizado por possuir pelo menos um dos oito genes mutantes que afetam a síntese de carboidratos no endosperma. Os principais genes são "Shrunken-2" (sh2) localizado no cromossomo 3, "Brittle" (bt), no cromossomo 5, e "Sugary Enhancer" (se), "Sugary" (su) e "Brittle2" (bt2), todos no cromossomo 4. Existem ainda os genes "Dull" $(d u)$, no cromossomo 10, "Waxy" (wx), no cromossomo 9, e "Amylose Extender" (ae), no cromossomo 5. Todos podem atuar de forma simples ou em combinações duplas ou triplas (Tracy, 1994). Genótipos sul possuem em média 30\% a menos de proteína que genótipos $s h 2$ (Goldman \& Tracy, 1994).

A qualidade do milho-doce é avaliada não só pelo teor de açúcar como também pela textura dos grãos. A textura uma característica determinante na aceitação e condições de processamento (Scapim et al., 1995), uma vez que todas as cultivares de milho-doce apresentam engrossamento da textura no decorrer da maturação, em maior ou menor proporção (Gama \& Parentoni, 1992).

Atualmente, as lavouras de milho têm alcançado altos níveis de produti- vidade. Em 2003, o milho apresentou aumento de $34 \%$ na produção, alcançando 48,3 milhões de toneladas de grãos produzidos, quase a metade $(24,1 \mathrm{mi}$ lhões de toneladas) colhida na região Sul (IBGE, 2003). Essa evolução se deve ao desenvolvimento de tecnologia em diversas áreas, incluindo o melhoramento genético. $\mathrm{O}$ melhoramento do milho tem conseguido aumentar não somente a produtividade, mas também inserir outras características desejáveis na planta (Parteniani, 1988), como espigas grandes, cilíndricas, bem empalhadas e bem granadas; grãos tipo dentado, de cor amarela e profundos; estigmas claro e soltos; sabugo de coloração branca e grãos com endurecimento relativamente lento, possibilitando período de colheita mais longo, sendo essas características necessárias para recomendação de cultivar para o consumo in natura (Fornasieri-Filho, 1992). Características indesejáveis do milho-doce também es- 
tão sendo atenuadas utilizando o melhoramento genético, como o déficit germinativo, baixa produtividade e alta susceptibilidade ao ataque de pragas e doenças (Scapim et al., 1995; Alexander \& Creech 1977).

A alta tecnologia que vem sendo empregada no cultivo do milho-doce, assim como sua utilização pela indústria, requer cultivares que, além de produtivas, sejam uniformes quanto à maturação, tamanho e formato de espigas (Parentoni et al., 1990). Em relação ao consumidor, as características mais exigidas são a coloração amareloalaranjada e o pericarpo mais fino, que contribui para a maciez do grão (Lemos et al., 1999).

O milho é a espécie de maior diversidade genética na natureza (Bull, 1993). Isso facilita a exploração da heterose, especialmente em programas que almejem o desenvolvimento de cultivares. Existem entre outros, dois grupos heteróticos principais, denominados de duro e dentado. A maioria dos híbridos de milho pertence a tais grupos heteróticos (Fancelli \& Dourado Neto, 1996). Em programas de seleção recorrente recíproca, o melhoramento ocorre simultaneamente em ambas populações, ampliando a cada ciclo, o potencial genético das populações e das linhagens derivadas e, consequentemente, dos híbridos resultantes (Eyherabide \& Hallauer, 1991).

O melhoramento genético do milhodoce pode ser resumido em duas ações: introdução do caráter doce (monogênico recessivo) a partir de uma fonte genética qualquer em um material de endosperma normal ou utilização de germoplasma doce em um programa de melhoramento de rotina (Parentoni et al., 1990).

O método de retrocruzamento é a principal ferramenta para incorporar características monogênicas. $\mathrm{O}$ método se baseia em introduzir um gene de interesse, como o caráter doce, em determinado material genético superior, através de cruzamentos com a fonte do gene desejado, seguido de cruzamentos sucessivos com o parental superior. O objetivo do método é recuperar o genótipo do genitor recorrente, exceto para uma ou poucas características que o melhorista procura transferir a partir do genitor doador (Borém, 2001).

O objetivo deste trabalho foi obter híbridos de milho-doce (sul) de alta produtividade por meio de retrocruzamento, caracterizar morfológica e agronomicamente os híbridos e seus progenitores e obter a estimativa da heterose para os caracteres avaliados.

\section{MATERIAL E MÉTODOS}

\section{Material Genético}

Foram utilizadas as linhagens Docede-Cuba e 43IN, obtidas do banco de germoplasma da Universidade Federal de Viçosa (UFV), e as populações Piranão-8 e Cimmyt-8, fornecidas pelo banco de germoplasma da Universidade Estadual do Norte Fluminense (UENF).

O gene mutante sul, responsável pelo sabor doce no milho foi transferido a partir das linhagens de milho-doce 43 IN e Doce-de-Cuba para as populações de milho comum Cimmyt- 8 e Piranão-8. A introgressão do gene e a estabilidade foram obtidas através de cinco ciclos de retrocruzamento, em que se recuperou $98,45 \%$ do genoma recorrente. De posse dos dois conjuntos de indivíduos de milho-doce retrocruzados, realizou-se o cruzamento entre os mesmos visando à obtenção de híbridos (Tabela 1).

\section{Delineamento Experimental e Tratos Culturais}

Para verificar o desempenho dos híbridos obtidos, realizou-se o plantio das onze populações no mês de setembro de 2003, utilizando-se delineamento em blocos ao acaso, com duas repetições e parcelas formadas por quatro fileiras de 5 metros de comprimento cada, com espaçamento de $1,00 \times 0,20 \mathrm{~m}$ entre linhas e plantas, respectivamente. Foram utilizados dois ambientes distintos: Colégio Agrícola Antônio Sarlo, localizado em Campos dos Goytacazes, e PESAGRO-RJ, na Ilha Barra do Pomba, em Itaocara, RJ. Campos dos Goytacazes situa-se no Norte do Estado do Rio de Janeiro, a $21^{\circ} 45^{\prime} \mathrm{S}, 41^{\circ}$ 20' W e $11 \mathrm{~m}$ de altitude (Oliveira, 1996). O clima é classificado como tropical chuvoso, de bosque (Am) com uma precipitação média anual de $1023 \mathrm{~mm}$, evapotranspiração potencial de 1601 $\mathrm{mm}$ anuais e temperatura média anual de $23^{\circ} \mathrm{C}$ (Ometto, 1981). Itaocara localiza-se na Região Noroeste Fluminense, a $21^{\circ} 39^{\prime} 12^{\prime \prime} \mathrm{S}, 42^{\circ} 04^{\prime} 36^{\prime \prime} \mathrm{W}$ e $60 \mathrm{~m}$ de altitude. O clima do tipo Awi, com temperatura média anual de $22,5^{\circ} \mathrm{C}$ e precipitação média anual de $1041 \mathrm{~mm}$ (Fontes, 2001).

A semeadura foi feita manualmente, utilizando-se três sementes/cova, $0,02 \mathrm{~m}$ de profundidade. Utilizou-se irrigação por aspersão, duas vezes por semana, por um período de duas horas, com aspersor de $3 \mathrm{~m}^{3}$ hora $^{-1}$ de lâmina d'água. Durante o ciclo das plantas, foi realizado um desbaste, 25 dias após a semeadura, deixando uma planta por cova. Para o controle de ervas daninhas utilizou-se capina e controle químico.

\section{Determinações Agronômicas}

Foram avaliadas as seguintes características: $\mathrm{n}^{\mathrm{o}}$ de espigas por parcela (NE), porcentagem de espigas atacadas por pragas (EAP), diâmetro da espiga (DE), diâmetro do sabugo (DS), comprimento do grão (CG), $\mathrm{n}^{\circ}$. de fileiras de grãos (NFG), comprimento da espiga com palha (CECP), comprimento da espiga sem palha (CESP) e produtividade sem palha ( $\mathrm{PrE}$ ). As espigas foram colhidas 23 dias após a polinização. Para DE, DS, CG, NFG, CECP e CESP utilizou-se a média das cinco melhores espigas da fileira. Foram avaliadas ainda a altura de planta (AP), medida em oito plantas por parcela a partir do nível do solo até o nó da inserção do pendão; altura de inserção espiga principal (AE), medida em oito plantas por parcela a partir do nível do solo até a inserção da espiga principal; $\mathrm{n}^{\mathrm{o}}$ de plantas por fileira (NP), obtido pela contagem das plantas de cada parcela na época da colheita; $n^{\circ}$ de folhas da planta (NF), medidas em oito plantas por parcela; $\mathrm{n}^{\mathrm{o}}$. de dias para o florescimento (do plantio ao florescimento) (NDF); $\mathrm{n}^{\mathrm{o}}$ de dias para colheita (do plantio a colheita) (NDC); $\mathrm{n}^{\text {o. }}$ de plantas acamadas (NPA), obtido pela contagem das plantas de cada parcela e; $n^{\text {o. }}$ de plantas quebradas (NPQ), obtido pela contagem das plantas quebradas de cada parcela. A determinação dos valores da heterose foi realizada através da comparação de cada híbrido com o valor da média dos pais e com o valor do pai mais produtivo. 
Os resultados de todas as características foram submetidos a análise Univariada, por local e conjuntamente, e o DMS foi calculado pelo teste $\mathrm{t}$ de Student, a 5\% de probabilidade, utilizando-se para tanto o programa estatístico SAS (SAS, 1996).

\section{RESULTADOS E DISCUSSÃO}

A análise estatística univariada mostrou não haver interação genótipo $\mathrm{x}$ ambiente para nenhuma característica nos experimentos instalados em Itaocara e Campos dos Goytacazes (resultados não apresentados). Portanto, foi realizada a análise conjunta dos dados.

Neste trabalho não foram feitas inferências quanto aos ganhos de heterose do híbrido HDC, uma vez que a origem da linhagem PDC ainda está sob investigação. Algumas características apresentadas pela linhagem PDC a excluem do material genético selecionado para este trabalho, como, por exemplo, dias até o florescimento, em que a linhagem mostrou-se muito precoce, e altura das plantas, em que as plantas desta linhagem foram tão altas quanto plantas de materiais que não possuem o gene braquítico ( $b r 2)$.

As linhagens de milho-doce 43IN e Doce-de-Cuba foram mais suscetíveis ao ataque de pragas quando comparadas aos demais genótipos (Tabela 2). Anteriormente, Treat \& Tracy (1994) e Bordallo et al. (2005) haviam obtido resultados semelhantes. Considera-se que a maior susceptibilidade seja devido a uma maior concentração de açúcares e de outros atrativos nos grãos de milho-doce. A população Cimmyt-8 e o híbrido UENF506-8, com 28,7 e 25,7\% de espigas atacadas, respectivamente, apresentaram maior resistência ao ataque de pragas por possuírem endosperma amiláceo e rústico, menos atrativo que o endosperma doce (Bordallo et al., 2005). Dois outros materiais, a linhagem C43 (22,9\%) e o híbrido H43IN $(22,4 \%)$ também apresentaram resistência significativa quando comparados às linhagens $43 \mathrm{IN}(60,0 \%)$ e Doce-de-Cuba $(55,6 \%)$. Por outro lado, as linhagens P43 (42,0\%) e PDC $(35,7 \%)$, assim como a população Piranão-8 (36,6\%), apresentaram um

Tabela 1. Caracterização de materiais de milho. Campos dos Goytacazes, UENF, 2003-2004.

\begin{tabular}{lllll}
\hline Genótipo & Procedência & Classificação & Porte & Tipo de população \\
\hline $43 I N$ & UFV & Doce & Alto & Genitor doador (linhagem) \\
P43 & UENF & Doce & Baixo & RC5 Piranão-8 x 43IN \\
C43 & UENF & Doce & Baixo & RC5 Cimmyt x 43IN \\
H43IN & UENF & Doce & Baixo & Híbrido Simples (C43 x P43) \\
Doce-de-Cuba & UFV & Doce & Alto & Genitor doado (linhagem) \\
PDC & UENF & Doce & Baixo & RC5 Piranão-8 x Doce-de-Cuba \\
CDC & UENF & Doce & Baixo & RC5 Cimmyt x Doce-de-Cuba \\
HDC & UENF & Doce & Baixo & Híbrido Simples (CDC x PDC) \\
Piranão-8 (P8) & UENF & Dentado & Baixo & Genitor recorrente (população) \\
Cimmyt-8 (C8) & UENF & Duro & Baixo & Genitor recorrente (população) \\
UENF506-8 & UENF & Semi-dentado & Baixo & Híbrido Simples (C8 x P8) \\
\hline RC:
\end{tabular}

${ }^{1} \mathrm{RC}$ : retrocruzamento.

Tabela 2. Espigas atacadas por pragas (EAP), diâmetro da espiga (DE), diâmetro do sabugo (DS), comprimento do grão (CG), número de fileiras de grãos (NFG), comprimento da espiga com (CECP) e sem palha (CESP) e produtividade sem palha (PrE) de onze populações de milho. Campos dos Goytacazes, UENF, 2003-2004.

\begin{tabular}{|c|c|c|c|c|c|c|c|c|}
\hline \multirow{2}{*}{ Genótipo } & \multirow{2}{*}{$\begin{array}{l}\text { EAP } \\
(\%)\end{array}$} & DE & DS & CG & \multirow{2}{*}{ NFG } & CECP & CESP & \multirow{2}{*}{$\begin{array}{c}\operatorname{PrE} \\
\left(\mathrm{t} \mathrm{ha}^{-1}\right)\end{array}$} \\
\hline & & & $(\mathrm{cm})$ & & & \multicolumn{2}{|c|}{ (cm) } & \\
\hline $43 \mathrm{IN}$ & 60,0 & 4,7 & 2,9 & 1,8 & 18,1 & 25,2 & 16,5 & 5,98 \\
\hline P43 & 42,0 & 4,4 & 2,5 & 2,0 & 12,9 & 28,4 & 17,0 & 6,36 \\
\hline C43 & 22,9 & 4,5 & 2,5 & 2,0 & 13,0 & 29,4 & 18,6 & 6,58 \\
\hline $\mathrm{H} 43 \mathrm{IN}$ & 22,4 & 4,4 & 2,4 & 2,0 & 12,7 & 31,8 & 18,5 & 7,84 \\
\hline Doce-de-Cuba & 55,6 & 4,8 & 2,7 & 2,1 & 17,4 & 25,0 & 17,1 & 5,40 \\
\hline PDC & 35,7 & 4,3 & 2,4 & 2,0 & 13,8 & 25,9 & 17,3 & 6,26 \\
\hline CDC & 41,8 & 4,2 & 2,4 & 1,8 & 13,1 & 29,7 & 19,1 & 6,05 \\
\hline H DC & 38,6 & 4,2 & 2,4 & 1,8 & 12,7 & 27,4 & 17,6 & 7,62 \\
\hline Piranão-8 & 36,6 & 4,0 & 2,2 & 1,8 & 11,5 & 29,8 & 19,0 & 7,97 \\
\hline Cimmyt-8 & 28,7 & 4,1 & 2,3 & 1,8 & 13,1 & 29,1 & 20,1 & 8,33 \\
\hline UENF506-8 & 25,7 & 4,2 & 2,4 & 1,8 & 12,8 & 30,8 & 21,6 & 9,05 \\
\hline média geral & 36,6 & 4,3 & 2,5 & 1,9 & 13,7 & 28,4 & 18,4 & 7,04 \\
\hline DMS (teste t a $5 \%$ ) & 16,7 & 0,2 & 0,2 & 0,2 & 1,1 & 1,7 & 1,1 & 1,40 \\
\hline $\mathrm{H}(\%)$ & 54,5 & 95,5 & 93,9 & 90,2 & 92,3 & 94,0 & 94,2 & 80,3 \\
\hline CV (\%) & 31,2 & 6,8 & 9,3 & 15,0 & 11,8 & 9,1 & 8,8 & 13,3 \\
\hline
\end{tabular}

$\mathrm{H}=$ Índice de determinação genotípica.

nível apenas intermediário de resistência, o que pode significar que a população Piranão, por apresentar grãos do tipo dentado, próximo a farináceo, seja menos resistente ao ataque de pragas que as populações de grãos duros (Pereira, 2004. Comunicação pessoal). Verificouse também que a resistência tendeu a permanecer nas linhagens obtidas por retrocruzamento, demonstrando que a resistência do genitor recorrente foi recuperada após cinco ciclos do retrocruzamento. Quanto aos híbridos, além de apresentarem boa resistência ao ataque de pragas (Tabela 2), apresentaram heterobeltiose elevada, de 30,9\% e
21,1\% para H43IN e UENF506-8, respectivamente (Tabela 3 ).

Os materiais genéticos que possuem o gene mutante sul apresentaram espigas e sabugos de maior diâmetro (Tabela 2), sendo esta uma característica própria do milho-doce. Verificou-se também que para tais características, o híbrido doce não apresentou heterose, enquanto o híbrido comum apresentou heterobeltiose (3,0 e 5,7\%, para diâmetro da espiga e do sabugo, respectivamente). Para o comprimento dos grãos, o híbrido doce apresentou heterobeltiose de $2,0 \%$, enquanto o híbrido comum não apresentou heterose significativa (Tabela 3). 
Tabela 3. Estimativa da heterose (\%) de cruzamentos, entre as linhagens de milho obtidas por retrocruzamento P43 e C43 e entre as populações genitores recorrentes Piranão-8 e Cimmyt-8. Campos dos Goytacazes, UENF, 2003-2004.

\begin{tabular}{lcc}
\hline Característica & UENF506-8 (\%) & H43IN (\%) \\
\hline Espigas atacadas por pragas (\%) & 21,1 & 30,9 \\
Diâmetro da espiga & 3,0 & 1,8 \\
Diâmetro do sabugo & 5,8 & 4,8 \\
Comprimento do grão & 0,6 & 2,0 \\
Número de fileiras de grãos & 3,7 & 1,9 \\
Comprimento da espiga com palha & 4,8 & 10,0 \\
Comprimento da espiga sem palha & 10,4 & 4,4 \\
Produtividade de espigas sem palha & 11,0 & 21,1 \\
Altura de planta & 1,2 & 1,1 \\
Altura de inserção da espiga principal & 4,9 & 5,6 \\
Número de plantas por fileira & 2,1 & 14,0 \\
Número de espigas por parcela & 0,7 & 9,2 \\
Número de folhas da planta & 2,2 & 1,4 \\
Número de dias do plantio ao florescimento & 0,0 & 0,4 \\
Número de plantas acamadas & 47,9 & 18,2 \\
Número de plantas quebradas & 70,5 & 22,7 \\
\hline
\end{tabular}

Observou-se também dois grupos de materiais bem distintos quanto ao número de fileiras de grãos (Tabela 2). Um grupo com maior número de fileiras, composto pelas duas linhagens doadoras (43IN e Doce-de-Cuba) e outro grupo, com menor número de fileiras, composto pelos demais materiais, mostrando novamente que cinco ciclos de retrocruzamento foram suficientes para recuperar a maioria dos genes recorrentes.

As características comprimento de espiga com palha (CECP) e comprimento de espiga sem palha (CESP), apresentaram efeitos de heterobeltiose (Tabela 3) para ambos os híbridos doce e comum, com efeito de $10,0 \%$ e $4,4 \%$ para CECP e CESP no híbrido H43IN, e $4,7 \%$ e $10,4 \%$ para CECP e CESP no híbrido UENF506-8. Verificou-se, tanto com palha quanto sem palha, que o milho comum apresentou maiores espigas e que os genótipos doadores apresentaram os menores comprimentos. Verificou-se o maior efeito (presença) dos genes do genótipo doador nos retrocruzados, fazendo com que eles apresentassem menor comprimento que as populações Piranão-8 e Cimmyt-8 (Tabela 2). Desta forma, pode-se caracterizar os materiais de milho-doce (43IN e Doce-de-Cuba) como aqueles de maior diâmetro de espiga e de sabugo, maior número de fileiras de grãos, menor comprimento de espigas com palha e sem palha, e, para a linhagem Doce-de-Cuba, maiores grãos.

Determinadas características da espiga são indispensáveis durante a comercialização de milho-verde, seja para a indústria (na forma de enlatado) ou para o consumidor (in natura), que adquire o produto com base principalmente no tamanho e qualidade das espigas (Gama et al., 1983; Viana et al., 1983). Desta forma, os produtores de milho-verde, seja milho-doce ou milho comum, procuram sempre cultivares que possuam espigas atrativas, ou seja, espigas despalhadas maiores que $15 \mathrm{~cm}$ de comprimento, diâmetro superior a 3 $\mathrm{cm}$ e isentas de pragas e doenças (Paiva Júnior et al., 2001). Por esses critério, pode-se constatar que todos os onze materiais são classificados como comerciais para comprimento e diâmetro, sobressaindo as populações de milho comum e os híbridos de milho-doce (Tabela 2). Para resistência ao ataque de pragas e doenças, o híbrido 43IN e a linhagem Doce-de-Cuba não poderiam ser recomendados.

Além dos atributos comerciais, a produtividade é uma característica de extrema importância. No presente trabalho observou-se que as médias para produtividade (PrE) dos híbridos avaliados, H43IN (7,83 t ha-1) e HDC (7,62 $\left.\mathrm{t} \mathrm{ha}^{-1}\right)$, apresentaram melhoras significativas em relação aos genitores doado- res $\left(5,97\right.$ e 5,40 $\mathrm{t} \mathrm{ha}^{-1}$ respectivamente) (Tabela 2). O híbrido H43IN expressou heterobeltiose de $21,1 \%$ sobre seus parentais (Tabela 3). Os híbridos UENF506-8 (9,05 t ha-1) e H43IN (7,83 t ha $^{-1}$ ) foram os mais produtivos, não apresentando diferença significativa entre si (Tabela 2). O híbrido HDC foi ligeiramente inferior $\left(7,62 \mathrm{t} \mathrm{ha}^{-1}\right)$, o suficiente para diferir estatisticamente do híbrido UENF506-8, que apresentou ganho de heterobeltiose de 11,0\% (Tabela 3).

Segundo Borém (2001) valores de coeficiente de determinação genotípica (H) maiores que $80 \%$ indicam que os indivíduos selecionados para tais características (DE, DS, CG, NFG, CECP, CESP e PrE) possuem variabilidade devida ao genótipo, ou seja, mais de $80 \%$ da variabilidade genética é devido ao efeito predominantemente do genótipo (Tabela 2). Já para a característica de espigas atacadas por pragas essa influência não foi tão acentuada (54,5\%), podendo ainda ser considerada de média influência genotípica.

Com relação à altura de plantas (Tabela 4), o híbrido 43IN e a linhagem Doce-de-Cuba (186 cm e $178 \mathrm{~cm}$ ) apresentaram altura superior aos demais materiais, o que era esperado, pois esses dois genótipos não possuem o gene braquítico (br2), responsável pela redução do porte da planta. Verificou-se, assim, que durante o retrocruzamento, o gene braquítico foi totalmente recuperado. Para o caráter altura de inserção de espiga principal (Tabela 3), os híbridos H43IN e UENF506-8 apresentaram ganho de heterose de $5,6 \%$ e $4,9 \%$, respectivamente.

O número de plantas por parcela (Tabela 4) não apresentou diferença significativa, variando de 21 a 24,7 plantas por fileira de cinco metros. O híbrido H43IN apresentou um ganho de heterobeltiose de $13,9 \%$, enquanto que o híbrido UENF506-8 apresentou heterose de $2,1 \%$.

Com relação ao número de espigas (Tabela 4), pôde-se distinguir três grupos: o primeiro composto pelos materiais 43IN e Doce-de-Cuba com 21,2 e 20,2 espigas por fileira, respectivamente; o segundo grupo composto pelos materiais Piranão-8, Cimmyt- 8 e UENF506-8 que apresentaram 33,5, 
34,0 e 34,0 espigas por fileira, respectivamente; e o terceiro grupo, intermediário aos dois anteriores, composto pelo restante dos materiais, onde o número de espigas por fileira variou entre 24,0 e 28,5. Em relação a esta característica, o híbrido H43IN apresentou ganho de heterobeltiose de $9,2 \%$, enquanto o híbrido UENF506-8 apresentou heterose de $0,7 \%$ (Tabela 3 ).

Os materiais de milho-doce $43 \mathrm{IN}$ e Doce-de-Cuba, por não possuírem gene braquítico, são de maior porte e apresentam maior espaçamento entre os internódios. Consequentemente, possuem menor quantidade de folhas por planta (Tabela 4). Em relação a esta característica, observou-se a formação de dois grupos bem distintos, um composto pelos materiais de milho-doce e, o outro, pelos demais materiais, portadores do gene braquítico.

O número de dias para o florescimento e número de dias para colheita (Tabela 4) praticamente não diferiram entre os materiais avaliados, com exceção da linhagem PDC, cuja procedência não é totalmente esclarecida. Os materiais avaliados não diferiram entre si em relação ao número de plantas acamadas e de plantas quebradas (Tabela 4).

Observando as características altura de plantas, altura de espigas, número de espigas, número de folhas, número de dias para o florescimento e número de dias para a colheita verificou-se que o índice de determinação genotípica, $\mathrm{H}$, apresentou forte influência do genótipo, superior a $84 \%$ (Tabela 4). Já para a característica de número de plantas, número de plantas acamadas e número de plantas quebradas a influência genotípica foi menor.

\section{AGRADECIMENTOS}

Os autores agradecem a FAPERJ (Fundação de Apoio a Pesquisa do Estado do Rio de Janeiro) pelo auxílio financeiro concedido; a E.E. da PESAGRO-RJ (Itaocara) e ao Colégio Agrícola Antônio Sarlo (Campos dos Goytacazes), pela oportunidade de implementar os experimentos de campo, e ao técnico agrícola Geraldo Francisco de Carvalho, pelo auxílio em to-

Tabela 4. Altura de planta (AP), altura de inserção de espiga principal (AE), número de plantas por parcela $(\mathrm{NP})$, número de espigas $(\mathrm{NE})$, número de folhas $(\mathrm{NF})$, número de dias para o florescimento (NDF), número de dias para colheita (NDC), número de plantas acamadas (NPA) e número de plantas quebradas (NPQ) de onze populações de milho. Campos dos Goytacazes, UENF, 2003-2004.

\begin{tabular}{|c|c|c|c|c|c|c|c|c|c|}
\hline \multirow{2}{*}{ Genótipo } & AP & $\mathrm{AE}$ & \multirow{2}{*}{ NP } & \multirow{2}{*}{ NE } & \multirow{2}{*}{ NF } & NDF & NDC & \multirow{2}{*}{ NPA } & \multirow{2}{*}{ NPQ } \\
\hline & \multicolumn{2}{|c|}{ (cm) } & & & & \multicolumn{2}{|c|}{ (dias) } & & \\
\hline $43 I N$ & 186,3 & 119,7 & 22,3 & 21,3 & 11,0 & 65,0 & 87,5 & 2,5 & 2,0 \\
\hline P43 & 171,8 & 92,0 & 22,0 & 25,0 & 13,2 & 67,0 & 88,0 & 3,0 & 1,5 \\
\hline $\mathrm{C} 43$ & 168,2 & 98,2 & 21,0 & 24,0 & 13,3 & 66,5 & 88,0 & 2,5 & 1,8 \\
\hline $\mathrm{H} 43 \mathrm{IN}$ & 168,1 & 100,4 & 24,5 & 26,8 & 13,4 & 67,0 & 88,0 & 2,3 & 2,0 \\
\hline DC & 178,3 & 105,5 & 23,3 & 20,3 & 11,2 & 64,0 & 87,5 & 2,5 & 1,8 \\
\hline PDC & 187,0 & 106,8 & 23,3 & 22,8 & 10,4 & 60,5 & 82,5 & 2,3 & 1,8 \\
\hline CDC & 164,0 & 96,3 & 22,5 & 28,0 & 12,9 & 66,5 & 88,0 & 1,0 & 0,3 \\
\hline H DC & 168,2 & 106,3 & 23,3 & 28,5 & 13,0 & 66,5 & 88,0 & 1,3 & 1,0 \\
\hline Piranão-8 & 166,9 & 103,6 & 24,8 & 33,5 & 12,9 & 66,0 & 88,0 & 2,3 & 1,0 \\
\hline Cimmyt-8 & 162,1 & 99,5 & 23,3 & 34,0 & 12,9 & 66,0 & 88,0 & 1,5 & 0,8 \\
\hline Uenf506-8 & 166,5 & 106,5 & 24,5 & 34,0 & 13,2 & 66,0 & 88,0 & 2,8 & 1,5 \\
\hline média geral & 171,6 & 103,2 & 23,1 & 27,1 & 12,5 & 65,6 & 87,4 & 2,2 & 1,4 \\
\hline DMS (teste t $5 \%$ ) & 5,2 & 6,9 & 3,3 & 5,9 & 0,5 & 1,7 & 0,4 & 2,4 & 1,3 \\
\hline$H(\%)$ & 95,7 & 89,8 & 9,2 & 84,4 & 97,2 & 90,8 & 99,2 & 0,0 & 43,0 \\
\hline CV (\%) & 5,8 & 12,8 & 9,5 & 14,7 & 8,3 & 1,8 & 0,3 & 74,2 & 61,3 \\
\hline
\end{tabular}

$\mathrm{H}=$ Indice de determinação genotípica

das as etapas do experimento.

\section{REFERÊNCIAS}

ALEXANDER DE; CREECH RG. 1977. Breeding special industrial and nutritional types. In: SPRAGUE, GF (Ed). Corn and corn improvement. Madison: American Society of Agronomy. p. 363-390.

BORDALLO PN; PEREIRA MG; AMARAL JÚNIOR AT; GABRIEL APC. 2005. Análise dialélica de genótipos de milho doce e comum para caracteres agronômicos e proteína total. Horticultura Brasileira 23: 123-127.

BORÉM A. 2001. Melhoramento de plantas. Viçosa: Editora UFV. 547p.

BULL LT. 1993. Cultura do milho: fatores que afetam a produtividade. Piracicaba: POTAFOS. 301p.

EYHERABIDE GH; HALLAUER AR. 1991. Reciprocal full-sib recurrent selection in maize: direct and indirect responses. Crop Science, 31: 952-959.

FANCELLI AL; DOURADO NETO D. 1996. Milho: fisiologia da produção. In: SEMINÁRIO SOBRE FISIOLOGIA DA PRODUÇÃO E MANEJO DE ÁGUA E DE NUTRIENTES NA CULTURA DO MILHO DE ALTA PRODUTIVIDADE. Piracicaba: USP-ESALQ/ POTAFÓS. p. 1-29.

FONTES PSF. 2001. Adubação nitrogenada e avaliação de cultivares de banana (Musa spp) no Noroeste do Estado do Rio de Janeiro. Campos dos Goytcazes: UENF. 64p. (Tese mestrado).

FORNASIERI FILHO D. 1992. A cultura do milho. Jaboticabal: FUNEP. 273p.
GAMA EEG; MORO JR; MAGNAVACA R; VIANA RT; NASPOLINI FILHO V. 1983. Melhoramento do milho. In: EMPRESA BRASILEIRA DE ASSISTÊNCIA TÉCNICA E EXTENSÃO RURAL. Cultura do milho. Brasília: EMBRATER. p. 23-38.

GAMA EEG; PARENTONI SN. 1992. Melhoramento genético e cultivares de milho doce. In: Gama EEG. A Cultura do Milho Doce. Sete Lagoas: EMBRAPA - Centro Nacional de Pesquisa de Milho e Sorgo. p. 9-12 (Circular Técnica).

GOLDMAN IL; TRACY WF. 1994. Kernel protein concentration in sugary-1 and shrunken-2 sweet corn. HortScience 29: 209210

IBGE (Instituto Brasileiro de Geografia e Estatística). 2005, 03 de março. Municipal Agricultural Production-2003. Disponível em http://www.ibge.gov.br/english/presidencia/

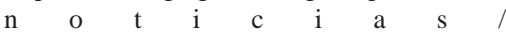
noticia_visualiza.php?id_noticia=259\&id_pagina=1.

LEMOS MA; GAMA EEG; PARENTONI SN; OLIVEIRAAC; REIFSHNEIDER FJB; SANTOS JPO; TABOSA JN. 1999. Capacidade geral e específica de combinação em híbridos simples de milho doce. Ciência $e$ Agrotecnologia 23: 48-56.

OLIVEIRA VPS. 1996. Avaliação do sistema de irrigação por sulco da fazenda do alto em Campos dos Goytacazes-RJ. Campos dos Goytacazes: UENF. 94p (Tese mestrado).

OMETTO JC. 1981. Bioclimatologia tropical. São Paulo: Agronômica Ceres. p. 390-398.

PAIVA JÚNIOR MC; VON-PINHO RG; VONPINHO EVR; RESENDE SGR. 2001. Desempenho de cultivares para a produção de milho verde em diferentes épocas e densidades de semeadura em Lavras - MG. Ciência e Agrotecnologia 25: 1235-1247. 
PATERNIANI E. 1988. Diversidade genética em plantas In: ENCONTRO SOBRE RECURSOS GENÉTICOS. Anais... Jaboticabal: UNESP-FCAVJ. p. 75-77.

PARENTONI SN; GAMA EEG; MAGNAVACA R; REIFSCHSNEIDER FJB; VILLAS-BOAS GL. 1990. Milho doce. Informe Agropecuário 14: $17-22$.

SAS, Statistical Analysis System, Versão 6.08. 1996. Cary: The SAS Institute.

SCAPIM CA; CRUZ CD; ARAÚJO JM. 1995. Cruzamentos dialélicos entre sete cultivares de milho-doce. Horticultura Brasileira 13: 19-21.
SOUZA IRP; MAIA AHN; ANDRADE CLT. 1990. Introdução e avaliação de milho doce na região do baixo Parnaíba. Teresina: EMBRAPA-CNPA. 7p.

TEIXEIRA FF; SOUSA IRP; GAMA EEG; PACHECO CAP; PARENTONI SN; SANTOS MX; MEIRELLES WF. 2001. Avaliação da capacidade de combinação entre linhagens de milho doce. Ciência e Agrotecnologia 25: 483-488.

TRACY WF. 1994. Sweet corn. In: Hallauer AR. Specialtry Corns. New York: CRC Press. p. 147-187.
TREAT CL; TRACY WF. 1994. Endosperm type effects on biomass production end on stalk and root quality in sweet corn. Crop Science 34: 396-399.

VALENTINI L; SHIMOYA A; COSTA CCS. 2002. Milho doce: viabilidade técnica de produção em Campos dos Goytacazes-RJ. PESAGRO-RJ. 14p (Comunicado técnico).

VIANA AC; SILVA AF; MEDEIROS JB; CRUZ JC; CORREA LA. 1983. Práticas culturais. In: EMPRESABRASILEIRADE ASSISTÊNCIA TÉCNICA E EXTENSÃO RURAL. Cultura do milho. Brasília: EMBRATER. p. 87-100. 